\title{
HOMENAJE A VERE GORDON CHILDE 1892 - 1987
}

Él era “... el mejor arqueólogo de prehistoria de nuestro tiempo". "De no haber sido por su profundo interés y extraordinaria capacidad para establecer las relaciones tiempo-espacio de tan vasta y compleja conformación de datos, los fundamentos del conocimiento de la Arqueología del Viejo Mundo nunca hubieran sido escritos". Además, "él hizo una serie de sugestivas y brillantes contribuciones a la teoría y método de la arqueología".

Las anteriores palabras tomadas de la revista de Hallam L. Movius, "Contribuciones a la arqueología prehistórica", ofrecidas al profesor V. Gordon Childe con motivo de su 65 cumpleaños, por 27 autores (Man, Vol. 57, Art. 42, pp 42-3, 1957), indican con exactitud la posición de Childe en nuestra profesión y sus principales aportes a la misma. Antropólogos de todo el mundo sentirán su pérdida. Falleció como resultado de una caída desde un acantilado en las Montañas Azules cerca de Sydney, Australia, el 19 de octubre de 1957. Acababa de retirarse de la Facultad de Arqueología de la Universidad de Londres y había regresado a su ciudad natal, Sydney, para permanecer seis meses de vacaciones, en los que tenía planeado escribir otro libro.

Este homenaje fue publicado por Irving Rouse en American Antiquity, Vol. 24, № 1, Julio 1958.
Childe nació en Sydney Norte el 14 de abril de 1892. Estudió Clásicos en la Universidad de Sydney y en 1914 obtuvo una colegiatura para después continuar su educación clasicista en la Universidad de Oxford, Inglaterra. Mientras permaneció allí hizo una investigación sobre elementos indoeuropeos en la Edad de Bronce en Grecia y a raíz de esto desarrolló su interés en la prehistoria de los Balcanes y Europa Oriental.

Después de la Primera Guerra Mundial regresó a su patria donde trabajó activamente en el Movimiento Australiano del Trabajo como secretario privado del Primer Ministro de Gales de Sur, desde 1919 hasta 1921. De esta primera experiencia nace su primer libro: Cómo gobierna el trabajo (Londres 1923).

Estas tempranas actividades anunciaron una aguda y conflictiva dicotomía en los intereses de Childe y su acercamiento académico, lo que persistió a través de toda su carrera. Por un lado era un humanista sumergido en los datos arqueológicos y más capaz de sintetizarlos desde el punto de vista histórico, que cualquier otro humanista de su generación. Por otro lado, era socialista, fuertemente influenciado por las teorías marxistas de la evolución, esto lo llevó a producir una serie de libros teóricos en los 
cuales interpreta los datos arqueológicos desde el punto de vista del Materialismo Dialéctico.

Sus intereses históricos fueron los primeros en dar frutos. Después de su labor relacionada con su trabajo, viajó mucho por Grecia, los Balcanes y Europa Central, examinando la Arqueología de esas áreas y estudiando la literatura, pudiendo leer, la mayor parte de esta en su idioma original. De esto salió El despertar de la Civilización Europea, en él sintetiza la Arqueología de Europa mostrando cómo los elementos de la civilización del Cercano Oriente y Mediterráneo se habían difundido hacia el resto del continente por el Norte. Publicado originalmente en 1925, este libro ha pasado por cinco revisiones, la última de las cuales fue publicada en 1957.

En 1925, año en el que apareció por primera vez El despertar, Childe se convirtió en Bibliotecario del Real Instituto Antropológico y en 1927 Profesor de Arqueología Prehistórica en el Universidad de Edimburgo. Hasta 1946 estuvo en este puesto para luego pasar a la Universidad de Londres como Catedrático de Arqueología Prehistórica y Director del Instituto de Arqueología, cargos de los que se acababa de retirar cuando murió.

En la década de 1930 recibió títulos honorarios de la Universidad de Harvard y de la Universidad de Pensilvania, trabajó como Profesor Visitante de la Universidad de California y en 1945, cuando se estaba convirtiendo en persona no grata por el Departamento de Estado debido a sus teorías marxistas, representó a Inglaterra en la celebración del $22^{2}$ aniversario de la Academia Soviética en Moscú y Leningrado.

A El despertar siguió una serie de libros en los cuales Childe demostró su talento como humanista e historiador. Sobresale entre estos últimos libros Nueva luz sobre el más antiguo oriente, en el que sintetizó la Arqueología del área tan vasta que cubre el desarrollo de los elementos de su civilización, antes de su difusión por el Mediterráneo y Europa. Como El despertar, este libro es un clásico dentro de su campo. Publicado originalmente en 1928 como El más antiguo Oriente, fue revisado y reeditado, en 1934, como su título actual y nuevamente en 1952. Otros trabajos de síntesis son El Danubio en la Prehistoria (1929), La Prehistoria de Escocia (1935) y Las comunidades prehistóricas en las Islas Británicas (1947). En Los arios (1926) Childe hizo un estudio arqueológico de origen y desarrollo de los indoeuropeos, volviendo sobre este tema en su Migraciones prehistóricas en Europa (1950). Nunca fue hombre de un solo campo, siendo su más grande trabajo sobre el mismo tema: Skara Brae: A Pictish Village in Orkney (1931).

El lado socialista y revolucionario de los intereses de Childe aparecieron en primer plano en 1935, cuando publicó El hombre se hace a sí mismo, un afamado trabajo por los conceptos sobre el Neolítico y Revoluciones Urbanas, el primero marcado por el cambio producido desde la recolección de alimentos y producción de los mismos, y el último por el desarrollo de la metalurgia, la escritura y otros atributos de la Civilización. Estas evoluciones son presentadas como eventos universales en la evolución de la cultura, a pesar de que están ilustradas como ejemplos tomados, casi en su totalidad, de la Arqueología de las áreas en las que Childe hizo su síntesis, especialmente el Cercano Oriente. En ¿Qué pasó en la Historia? (1942) combinó su sistema de revoluciones como los estados de Salvajismo, Barbarismo y Civilización de Lewis H. Morgan y los ilustró más completamente con ejemplos de la literatura arqueológica y en Progreso y Arqueología (1944) discutió la evolución desde el punto de vista tropical, que es, en términos de búsqueda de alimentación, entierros, herramientas, etc. más que en términos de periodos. En Historia (1947) trazó el desarrollo del método histórico, desde el tiempo prehistórico al Materialismo Dialéctico de Marx, finalizando con un tributo indirecto a Stalin, como expone de Marx. Terminó su Sociedad y conocimiento (1956) con al predicción de que el "ideal humanista" iba a convertirse, 
eventualmente, en subordinado del ideal de "Sociedad".

Considerando que los trabajos de síntesis histórica de Childe eran antes que nada indicativos, o sea que, sacó sus conclusiones de los datos, sus escritos evolucionarios tienden a ser deductivos, en esto asumió la teoría y hechos seleccionados de la Arqueología para ilustrarlos. Haciendo esto ignoró otros que eran contrarios a su teoría. Era demasiado buen prehistoriador para no reconocer la existencia de estos hechos conflictivos, y en 1951 publicó un nuevo estudio Evolución social en el cual, en efecto, repudiaba el tipo universal de evolución al cual sus tendencias socialistas lo habían previamente llevado. Examinando detalladamente las secuencias cronológicas en una serie de áreas que se extienden de Europa hasta el Cercano Oriente y el Valle del Nilo, llegó a la conclusión de que el proceso evolutivo había variado de área a área, dependiendo del medio ambiente local y las condiciones económicas y del proceso de difusión de la siguiente manera en "La Evolución de la Sociedad", publicada después de su muerte en Antiquity (№ 24, diciembre 1957, pp. 210-13).

Con la aceptación general de la evolución orgánica, también se aceptó la continuidad entre la historia humana y la historia natural. Esta última se convirtió en los últimos capítulos de un solo record histórico, tendiendo a la Arqueología como puente entre el record de las rocas y el record escrito. El contenido de estos últimos capítulos puede ser llamado como evolución social, y los mecanismos darwinianos de la variación, adaptación y su pervivencia pueden ser invocados para dilucidar la historia del hombre como también la de otros organismos. Pero, mientras que el uso de estos términos pueda dar énfasis a la continuidad de la historia, puede causar también confusión y desviar algunos jóvenes antropólogos y arqueólogos cuando tratan de aplicar, sin criterio, fórmulas darwinianas a las sociedades y artefactos humanos. De hecho, la intrusión de la difusión como agente de la evolución ha al- terado tan drásticamente el proceso histórico que no es válida analogía entre la evolución de las especies y la evolución de las sociedades.

La doctrina de la evolución ha puesto a la historia humana muy por encima del dominio de la revelación milagrosa o de la ficción romántica. No ha proveído un agente extraño para reemplazar a los hechos o deidades desacreditadas, ni tampoco revelado un atajo hacia las conclusiones que deberían aclarar la colección de hechos.

Uno se pregunta si la carrera de Childe no puede contener una lección para los arqueólogos del nuevo mundo. Hay un curioso, aunque superficial paralelo entre el repudiado acercamiento universal a la evolución de Childe y las clasificaciones del desarrollo que están ahora de moda en la arqueología americana. Podrán estas últimas, con sus secuencias de estados que supuestamente son universales en todo el hemisferio occidental, que él mismo encontró limitadas a ser aplicadas únicamente en el Cercano Oriente; o será que las etapas del Nuevo Mundo, también tendrán que ser vistas como un erróneo "atajo hacia las conclusiones" y una manera insonora de "hacer obvia la colección, de hechos" restringidos en primer lugar en su aplicación, a los centros de la Civilización Indo-Americana?

Las conclusiones históricas específicas de Childe, limitadas como son a Europa y el Cercano Oriente y al período protohistórico no nos concierne aquí. Sin embargo, sus métodos de síntesis histórica son pertinentes. iCuán a menudo se ha dicho que el Nuevo Mundo necesita un Childe para sinterizar el resultado de nuestras investigaciones!

A pesar de que él sumarizó su metodología en Reconstruyendo el pasado (1956) esto puede difícilmente hacerle justicia, probablemente porque él tendía a trabajar intuitivamente. Sin lugar a dudas, sus síntesis están caracterizadas por escasez de herramientas conceptuales, siendo la principal el concepto de una cultura 
correspondiendo a eso un foco o a una fase en este país. Para determinar las fechas de las culturas se apoyó primero en "sincronismos" con arqueología histórica, quiere decir que él buscó tipos de artefactos comunes a ambos, a las culturas prehistóricas y a las civilizaciones contemporáneas y asignó las fechas a los primeros y a los últimos. Conceptos "integrativos" como horizontales y tradicionales no tenían lugar en esta síntesis. Él tendió a dar relieve a la supervivencia de las formas tempranas de cultura en las periferias en lugar de darle importancia al principio de que similaridades indican necesariamente contemporaneidad, y fue sensible a la posibilidad de que dos culturas puedan haber coexistido en una misma área. Fue él quien por primera vez sugirió que las culturas forestales eran distintas de la "Mesolítico" en diferentes medios ambientes, una distinción posteriormente elaborada por Grahame Clark en The Mesolithic Settlement of Northern Europe (1936).

Los trabajos de síntesis de Childe son -a menudo- difíciles de leer debido a la extrema atención que él ponía en los detalles, no sólo de la cultura material sino también en las implicaciones no-materiales de los restos a los cuales su orientación marxista lo llevó a prestarles más atención que los demás arqueólogos de su generación, Sin embargo, sus síntesis están bien organizadas en lo que se refiere a su forma narrativa y el todo nunca incursiona en muchos detalles. Por último, fue su conocimiento enciclopédico de los hechos de la Arqueología y su habilidad para digerirlos, que lo hicieron un extraordinario sintetizador. 